\title{
(C) OPEN ACCESS \\ How well does the capillary thyroid-stimulating hormone test for newborn thyroid screening predict the venous free thyroxine level?
}

\author{
Tzveta Pokrovska, ${ }^{1}$ Jeremy Jones, ${ }^{2}$ M Guftar Shaikh, ${ }^{2}$ Sarah Smith, ${ }^{3}$ \\ Malcolm D C Donaldson ${ }^{1}$
}

\begin{abstract}
Section of Child Health, University of Glasgow School of Medicine, Royal Hospital for Children, Queen Elizabeth University Hospital, Glasgow, UK

${ }^{2}$ NHS Greater Glasgow and Clyde, Royal Hospital for Children, Queen Elizabeth University Hospital, Glasgow, UK

${ }^{3}$ Newborn Screening Laboratory, West of Scotland Genetic Services, Queen Elizabeth University Hospital, Glasgow, UK
\end{abstract}

\section{Correspondence to} Dr Malcolm D C Donaldson, Child Health Section of University of Glasgow School of Medicine, Queen Elizabeth University Hospital, Govan Road, Glasgow, G51 4TF, UK; malcolm.donaldson@glasgow. ac.uk

Received 10 August 2015 Accepted 15 January 2016 Published Online First 10 March 2016

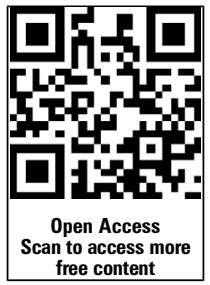

\section{CrossMark}

\section{To cite: Pokrovska $T$,}

Jones J, Shaikh MG, et al.

Arch Dis Child

2016;101:539-545.

\section{ABSTRACT}

Objectives To determine, in newborn infants referred with elevated capillary thyroid-stimulating hormone (TSH), a threshold below which a frankly subnormal venous free thyroxine (fT4) level of $<10 \mathrm{pmol} / \mathrm{L}$ is unlikely, so that treatment with levo-thyroxine (L-T4) might be deferred until venous thyroid function tests (TFTs) become available.

Subjects and methods All infants referred in Scotland since 1979 with capillary TSH elevation were studied, with particular focus on infants screened using the AutoDELFIA assay between 2002 and 2013.

Results Of the 321 infants referred with capillary TSH elevation using AutoDELFIA, 35 were excluded (fT4/TSH unavailable (12), venous sample either preceding or $>10$ days after capillary sampling $(13,10))$, leaving 286 eligible for analysis (208 definite/probable

hypothyroidism, 61 transient TSH elevation, 17 of uncertain thyroid status). Capillary TSH and venous T4 were strongly correlated (Spearman's rank correlation coefficient -0.707355$)$. The optimal capillary TSH threshold for predicting a venous fT4 of $<10 \mathrm{pmol} / \mathrm{L}$ was found to be $>40 \mathrm{mU} / \mathrm{L}$ ( $90.3 \%$ sensitivity and $65.9 \%$ specificity compared with $90.25 \%$ and $59.1 \%$ for $>35 \mathrm{mU} / \mathrm{L}$ and $88.3 \%$ and $68.2 \%$ for $>45 \mathrm{mU} / \mathrm{L}) .93$ infants (32.5\%) had capillary TSH $\leq 40 \mathrm{mU} / \mathrm{L}$ at referral of whom $15(9.7 \%)$ had venous fT4 $<10 \mathrm{pmol} / \mathrm{L}$, comprising seven with true congenital hypothyroidism, five with transient TSH elevation and three with uncertain status, two of whom died.

Conclusion For infants in whom capillary TSH is $\leq 40 \mathrm{mU} / \mathrm{L}$, it is reasonable to defer L-T4 treatment until venous TFT results are known provided that the latter become available quickly.

\section{INTRODUCTION}

Congenital hypothyroidism, the most common paediatric endocrine disorder, is very important clinically since severe cases will lead to irreversible mental handicap without prompt treatment. ${ }^{1}$ The reported incidence varies according to whether or not newborn screening is practised and if so by the cut-off used by the referring laboratory in terms of capillary thyroid-stimulating hormone (TSH) and thyroxine (T4). For example in Canada, where a capillary TSH threshold of $15 \mathrm{mU} / \mathrm{L}$ is used, the incidence of congenital hypothyroidism is 1 in 2600 births. $^{2}$ Although capillary TSH screening for primary congenital hypothyroidism, which began in Scotland in $1979,{ }^{3}$ has revolutionised the neurological outcome, some early treated infants still

\section{What is already known on this topic}

- Most newborn infants referred with capillary thyroid-stimulating hormone (TSH) elevation on newborn screening have congenital hypothyroidism requiring treatment with levo-thyroxine (L-T4).

- Some infants with capillary TSH elevation are found not to have congenital hypothyroidism so that treatment can either not be started or be discontinued.

\section{What this study adds}

- Infants in whom capillary TSH is $\leq 40 \mathrm{mU} / \mathrm{L}$ have a low probability $(10 \%)$ of having a subnormal venous free thyroxine level of $<10 \mathrm{pmol} / \mathrm{L}$.

- It is reasonable to defer L-T4 treatment in such infants until the results of venous thyroid function tests become available.

demonstrate a range of problems including subtle impairment of cognition, attention and memory deficit and vestibuloauditory problems, ${ }^{4-6}$ especially when postnatal care has been inadequate. ${ }^{6}$ Prompt treatment with levo-thyroxine (L-T4) of severe cases is therefore highly desirable.

When a newborn infant is referred with capillary TSH elevation, the physician needs to distinguish between congenital hypothyroidism requiring immediate treatment and milder thyroid dysfunction which may resolve without treatment. Following clinical assessment, a good venous blood sample for measurement of free thyroxine (fT4) and TSH is mandatory, since the result reflects the presence and severity of congenital hypothyroidism. ${ }^{7}$ However, at initial evaluation, only the capillary TSH value is available, and it may not be possible in all centres and in all countries to have the results of venous blood tests on the same day.

The crucial component of the venous blood sample is the T4 level, usually measured as fT4. Work of Mutlu et $a l^{8}$ in 296 newborns showed that on day 10 the 2.5 th centile, 50th centile and 97.5th centiles for fT4 were 15.2, 22.5 and $32 \mathrm{pmol} / \mathrm{L}$, respectively. It was on this basis that the 
European Society for Paediatric Endocrinology consensus group on congenital hypothyroidism defined the severity of hypothyroidism in terms of $\mathrm{fT} 4$ ranges, with $<5 \mathrm{pmol} / \mathrm{L}$ as severe, 5$10 \mathrm{pmol} / \mathrm{L}$ as moderate and $10-15 \mathrm{pmol} / \mathrm{L}$ as mild hypothyroidism. $^{7}$

When capillary TSH is grossly elevated, for example, $>100 \mathrm{mU} / \mathrm{L}$, with or without clinical features of hypothyroidism, the clinician will wish to start L-T4 treatment immediately since moderate or severe hypothyroidism is likely. The decision is less clear in an asymptomatic newborn with modest capillary TSH elevation, for example, $15-40 \mathrm{mU} / \mathrm{L}$, where venous fT4 is unlikely to be frankly low, and more likely to be either mildly subnormal $(10$ to $<15 \mathrm{pmol} / \mathrm{L}$ ) or within the newborn reference range of $15-32 \mathrm{pmol} / \mathrm{L}$. When the results of venous thyroid function tests (TFTs) will be available on the same day as venepuncture, the clinician can be guided by the fT4 levels. Although this same-day service will be routinely provided nowadays by laboratories in developed countries, the availability of venous results may still be problematic outside normal working hours and at weekends. Moreover, a same-day service may not be feasible in many countries with limited resources. In such situations, the clinician faces the dilemma as to whether to treat immediately or whether to await the venous results before committing the infant to several years of treatment with L-T4.

To date the relationship between capillary TSH levels measured in the course of newborn screening and serum thyroid hormone levels has not been explored. In this study, data from all infants referred by the Scottish Newborn Screening Programme with capillary TSH elevation has been reviewed with particular focus on infants evaluated by the AutoDELFIA assay since 2002. The aim is to determine a capillary TSH threshold below which decompensated primary hypothyroidism is unlikely so that immediate treatment with L-T4 is not indicated and can be deferred until venous TFT results become available.

\section{PATIENTS AND METHODS}

Since 1990, a computerised database has been kept of all infants referred by the newborn screening laboratory in Scotland since August 1979. ${ }^{39}$ This database records capillary TSH values (one, two or three samples depending on whether or not the laboratory have requested repeat tests) and venous total (t) T4 in nmol/ $\mathrm{L}$ (prior to 1996) and venous fT4 in pmol/L thereafter measured on the first assessment sample prior to starting LT-4 replacement.

Patients were classified as having definite congenital hypothyroidism, probable congenital hypothyroidism, transient TSH elevation and status uncertain, as previously described. ${ }^{3} 9$ The definitions for these four categories take into account the fact that thyroid imaging has not been consistently carried out in all Scottish centres since screening began, although combined radioisotope and ultrasound scanning has become the norm in the West of Scotland since $1996 .^{10}$

Analysis of capillary TSH and venous fT4 and tT4 data was carried out in relation to the four time periods during the study in which the assay and hence the normal, recall range and immediate referral cut-offs (mU/L) differed. These were:

- 1979-1982-Corning TSH radioimmunoassay (RIA): <25, $25-49,>50$

- 1982-1989-in-house TSH RIA: $<15,15-39, \geq 40$

- 1989-2002-ImmunoDiagnosticsSystems TSH immunoradiometric assay (IRMA): $<10,10-39, \geq 40$

- 2002-present-Perkin-Elmer TSH dissociation-enhanced lanthanide fluorescence immunoassay (DELFIA): $<8,8-24$, $\geq 25$
The entire cohort of patients from the 34-year period between August 1979 and December 2013 in whom both capillary and venous TSH data were available was analysed, followed by more detailed analysis of patients screened by the AutoDELFIA method from 2002 onwards. Total thyroxine values were converted to fT4 using an approximate in-house conversion division factor of 7.25. ${ }^{11}$ Where there were two samples from the same day, the second sample value was taken. Data were excluded when venous testing took place more than 10 days after the initial capillary sample test. In cases where the date of venous sampling was missing, it was calculated as age at notification plus 1 day, based on Scottish data showing that median age at notification and start of treatment were 12 versus 13.5 days in 344 patients from 1979 to 1993 and 10 versus 11 days in 250 patients from 1994 to 2003, indicating an approximate 1 day difference. ${ }^{9}$

\section{Statistical analysis}

The Shapiro-Wilk W test was initially used to test data for normality and indicated a non-normal distribution; therefore, nonparametric tests were used for data analysis, values being expressed as median with either range or IQR. Correlation between venous fT4 and capillary TSH were analysed using Spearman's rank correlation test and expressed as a coefficient of correlation with CIs. Receiver-operating characteristic (ROC) curve analysis was performed to explore the relationship between selected capillary TSH cut-offs and pretreatment venous fT4 levels, estimating the sensitivity and specificity at different capillary TSH cut-offs in predicting venous frank hypothyroidism, defined as $\mathrm{fT} 4<10 \mathrm{pmol} / \mathrm{L}$. The optimal capillary TSH threshold was identified as that which had the highest specificity in association with a sensitivity approaching 90\%. Venous fT4 data according to selected capillary TSH ranges were also expressed as 'box and whisker' plots using StatsDirect software (Altrincham, Cheshire, UK).

\section{Ethical aspects}

The Glasgow West Research Ethics Committee has previously approved data extraction from our database for audit and re-evaluation, provided that the data are anonymised. Since 2002, parents have given informed consent for data storage and for later anonymised data analysis and presentation. This project was registered with the Clinical Governance Support Unit of NHS Greater Glasgow and Clyde as a Quality Improvement Project.

\section{RESULTS}

\section{General information}

Between August 1979 and December 2013, 793 infants were referred by the screening laboratory and their outcome is shown in figure 1. Definite hypothyroidism was confirmed in 564 infants with probable hypothyroidism in 16, transient TSH elevation in 181 and status still uncertain in 32 . Of the 564 infants with true congenital hypothyroidism 177 (31.3\%) underwent a second capillary sample, while 7 (1.2\%) underwent a third capillary sample. Recall rates were higher for the 181 infants with transient TSH elevation, $88(48.6 \%)$ of whom required a second sample and $17(9.4 \%)$ a third sample. Age at venepuncture was missing in 23 of the 793 infants ( 9 with definite and one with probable congenital hypothyroidism, one with status uncertain and 12 with transient TSH elevation) so that this was derived from age at notification as described above.

Median (IQR) age at first capillary TSH testing was 6 days (5-7 days) for all infants and 6 days (5-7 days) after excluding 
infants with transient TSH elevation and status uncertain. A second capillary test was required in 177 infants, median (IQR) age at testing 16 days (13-21 days). For infants subsequently diagnosed with definite or probable hypothyroidism, median age at second testing was 15 days (12.5-19 days).

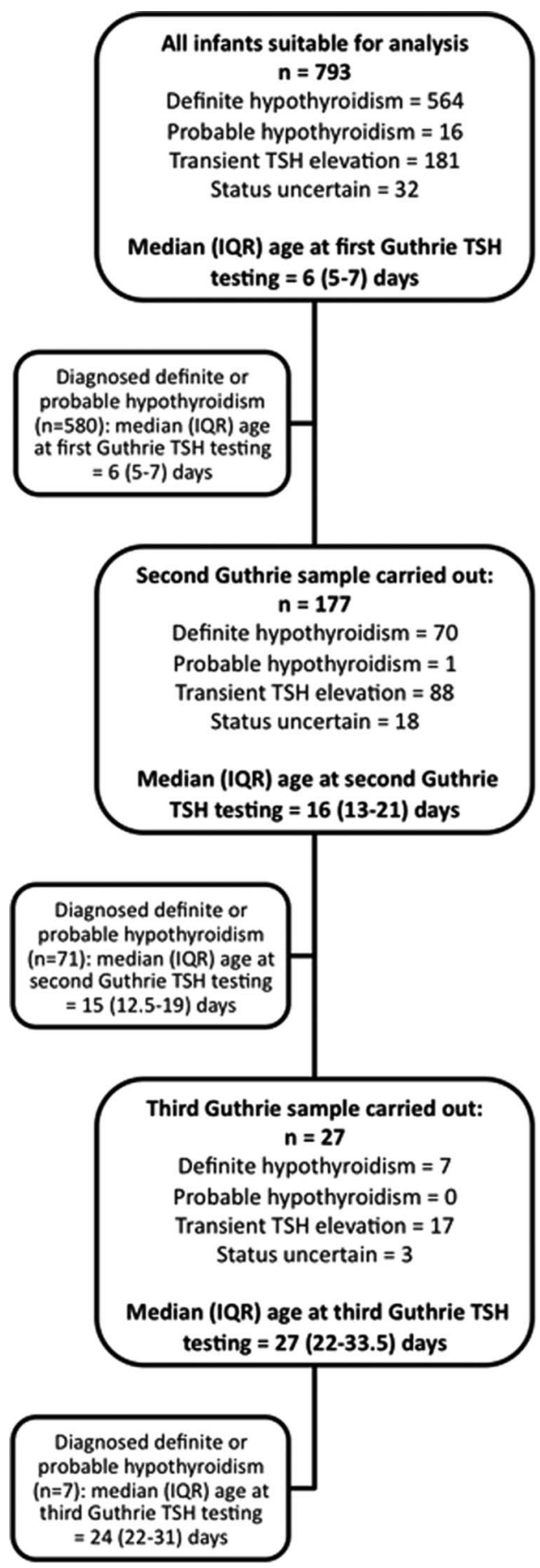

Figure 1 Consort diagram showing outcome in 793 infants referred with capillary thyroid-stimulating hormone (TSH) elevation by the Scottish Newborn Screening laboratory between August 1979 and December 2013. Note that the infants who had two capillary screening samples performed (middle large box) are also included in the upper box since all infants had one sample taken. Those infants who had three capillary samples performed (lower large box) are included in both preceding boxes.
A third capillary test was required in 27 infants, median (IQR) age 27 days (22-33.5 days). Of these, seven were diagnosed with definite hypothyroidism, median (IQR) age at third testing 24 days (22-31 days).

Analysis of cohort from 2002 onwards using the AutoDELFIA assay

Between January 2002 and December 2013, a total of 321 infants were referred by the Scottish Newborn Screening laboratory using the same AutoDELFIA assay. Thirty-five were excluded from analysis due to the age at venous sample $>10$ days after the capillary test (10 infants), venous TSH or fT4/tT4 unavailable (12 infants) and venous sample taken prior to first capillary sample (13 infants). This left 286 infants who met our criteria for analysis: 208 with definite and probable hypothyroidism, 61 with transient TSH elevation and 17 of uncertain thyroid status. Age at venepuncture was missing and hence derived from notification in one infant with definite congenital hypothyroidism and two with transient TSH elevation.

\section{Correlation between capillary TSH and venous fT4 testing}

There was a strong correlation between capillary TSH at screening and confirmatory venous fT4 testing following referral with a highly significant Spearman's rank correlation coefficient of $-0.707355(\mathrm{p}<0.0001,95 \%$ CI after using Fisher's Z transformed -0.760912 to -0.644225$)$.

Sensitivity and specificity of different capillary TSH cut-off levels in predicting low venous fT4

Table 1 and figure 2 show that a cut-off value of $>40 \mathrm{mU} / \mathrm{L}$ for capillary TSH gives a $90.3 \%$ sensitivity (95\% CI 84.4 to 94.4 ) and a $65.9 \%$ specificity (95\% CI 57.2 to 73.9 ) for predicting a venous fT4 value of $<10 \mathrm{pmol} / \mathrm{L}$, which would indicate the need for treatment with L-T4. Therefore, a capillary TSH cut-off of $>40 \mathrm{mU} / \mathrm{L}$ would detect $90.3 \%$ of those infants with frankly low venous fT4, while $65.9 \%$ of infants with fT4 $>10 \mathrm{pmol} / \mathrm{L}$ would have capillary TSH values of $\leq 40 \mathrm{mU} / \mathrm{L}$.

Table 1 Sensitivity and specificity of different capillary TSH cut-off levels in predicting a venous fT4 of $<10 \mathrm{pmol} / \mathrm{L}$ in 286 Scottish infants referred with capillary TSH elevation

\begin{tabular}{lll}
\hline $\begin{array}{l}\text { Capillary TSH cut-off } \\
\text { (mU/L whole blood) }\end{array}$ & Sensitivity & Specificity \\
\hline$>10$ & 0.987013 & 0.106061 \\
$>20$ & 0.961039 & 0.356061 \\
$>30$ & 0.922078 & 0.537879 \\
$>35$ & 0.902597 & 0.590909 \\
$>40$ & 0.902597 & 0.659091 \\
$>45$ & 0.883117 & 0.681818 \\
$>50$ & 0.857143 & 0.719697 \\
$>60$ & 0.831169 & 0.795455 \\
$>70$ & 0.818182 & 0.848485 \\
$>80$ & 0.792208 & 0.878788 \\
$>90$ & 0.75974 & 0.886364 \\
$>100$ & 0.746753 & 0.901515 \\
$>110$ & 0.74026 & 0.939394 \\
$>120$ & 0.694805 & 0.954545 \\
\hline
\end{tabular}

Sensitivity refers to the proportion of infants with $\mathrm{fT} 4$ of $<10 \mathrm{pmol} / \mathrm{L}$ whose capillary TSH is above a given cut-off value, while specificity refers to the proportion of infants with fT4 $\geq 10$ pmol/L whose capillary TSH is below the cut-off value. fT4, free thyroxine; TSH, thyroid-stimulating hormone. 
Figure 2 Receiver-operating characteristic curve analysis of capillary thyroid-stimulating hormone (TSH) levels predicting a venous free $\mathrm{T} 4$ value of $\leq 10 \mathrm{pmol} / \mathrm{L}$ in 286 newborn infants with TSH elevation on newborn screening.

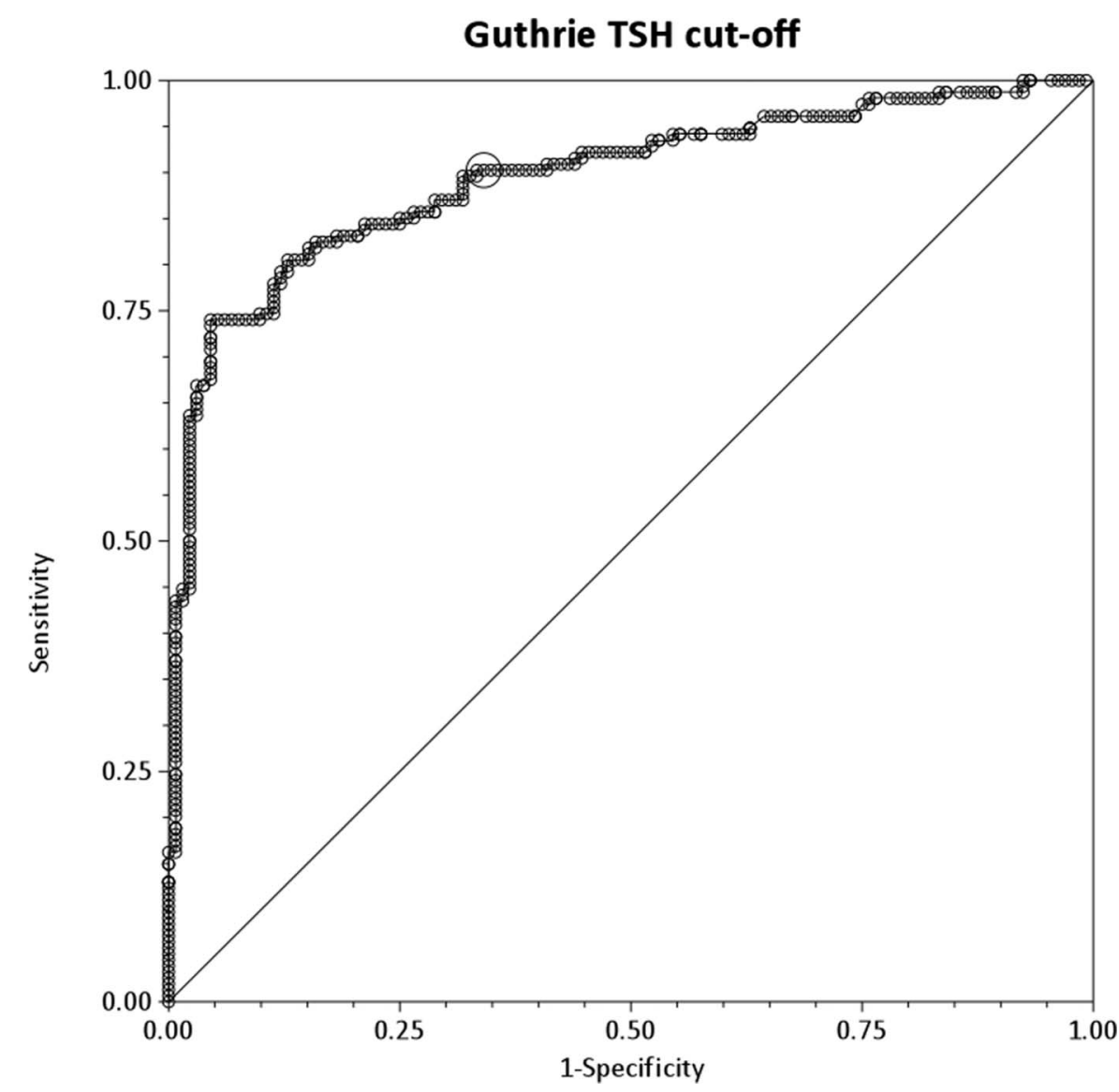

Moreover, the area under the ROC curve is 0.89 (95\% CI 0.86 to 0.93 ), indicating that referral capillary TSH is a strong predictor of subsequent fT4 values. A capillary TSH threshold of $>35 \mathrm{mU} / \mathrm{L}$ has almost identical sensitivity but lower specificity $(59.1 \%)$, while sensitivity is lower $(88.3 \%)$ for a cut-off of $>45 \mathrm{mU} / \mathrm{L}$ and specificity is lower $(53.8 \%)$ for a cut-off of $>30 \mathrm{mU} / \mathrm{L}$ compared with the $>40 \mathrm{mU} / \mathrm{L}$ cut-off.

Of the 286 infants analysed, $93(32.5 \%)$ had capillary TSH values of $\leq 40 \mathrm{mU} / \mathrm{L}$ at referral comprising 32 (11.1\%) with
TSH $25-40 \mathrm{mU} / \mathrm{L}$ at first testing and immediate referral; 57 (19.9\%) with TSH 8 to $\leq 25 \mathrm{mU} / \mathrm{L}$ on first sample and $8-40 \mathrm{mU} / \mathrm{L}$ at second sample prior to referral and 4 with TSH 8-40 $\mathrm{mU} / \mathrm{L}$ on third sample.

\section{Comparison between 1979-2001 and 2002-2013 data}

Data from 1979 to 2001 showed higher sensitivity $(96.4 \%$ vs $90.3 \%)$ but much lower specificity $(22.6 \%$ vs $65.9 \%)$ for
Figure 3 Median (range) venous free T4 according to range of capillary thyroid-stimulating hormone (TSH) in 286 infants with raised TSH on newborn screening.

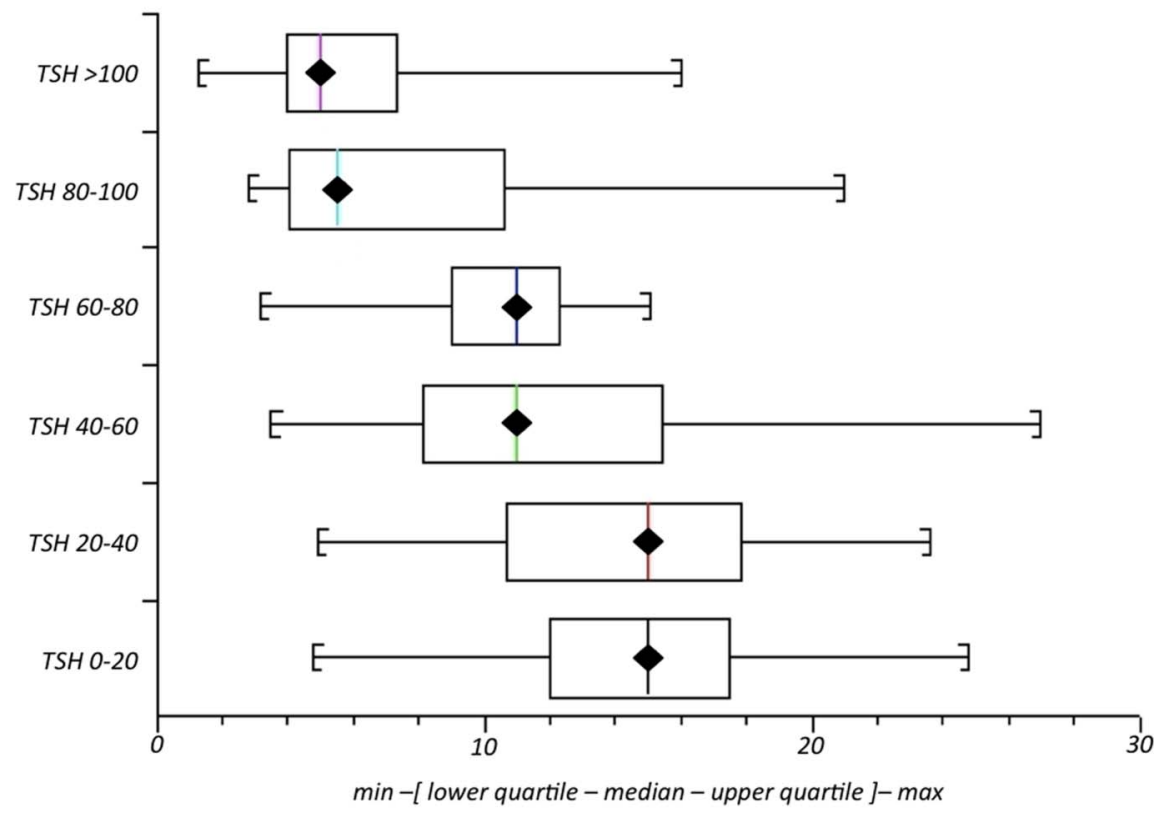


Table 2 Data on 15 infants referred with elevated capillary TSH in whom capillary TSH was $<40 \mathrm{mU} / \mathrm{L}$ and venous fT4 was $<10 \mathrm{pmol} / \mathrm{L}$

\begin{tabular}{|c|c|c|c|c|c|c|c|c|c|}
\hline $\begin{array}{l}\text { Patient } \\
\text { no. }\end{array}$ & $\begin{array}{l}\text { BW } \\
(\mathrm{kg})\end{array}$ & $\begin{array}{l}\text { GA } \\
\text { (weeks) }\end{array}$ & $\begin{array}{l}\text { Sick? } \\
(\mathrm{Y} / \mathrm{N})\end{array}$ & $\begin{array}{l}\mathrm{cTSH}(\mathrm{mU} / \mathrm{L}) \text { (age } \\
\text { in days) }\end{array}$ & $\begin{array}{l}\text { vTSH (mIU/L) } \\
\text { (age in days) }\end{array}$ & $\begin{array}{l}\text { vfT4 } \\
(\text { pmol/L) }\end{array}$ & Comment & $\begin{array}{l}\text { First cTSH (mU/L) } \\
\text { (age in days) }\end{array}$ & $\begin{array}{l}\text { Other cTSH (mU/L) } \\
\text { (age in days) }\end{array}$ \\
\hline \multicolumn{10}{|c|}{ True congenital hypothyroidism } \\
\hline 1 & 2.95 & 39 & $\mathrm{~N}$ & $9.5^{*}(12)$ & $22.7(18)$ & 4.8 & Probable dyshormonogenesis on radio-isotope scan & $23.2(5)$ & \\
\hline 2 & 4.22 & 42 & $\mathrm{~N}$ & $21.8^{*}(17)$ & $49.9(20)$ & 8.0 & Confirmed CH (rising TSH on diagnostic challenge) but no imaging performed & $9.42(5)$ & \\
\hline 3 & 3.54 & 39 & $\mathrm{~N}$ & $25.7(6)$ & $55.0(15)$ & 9.0 & Dyshormonogenesis (no mutation found) & & \\
\hline 4 & 2.8 & 40 & $\mathrm{~N}$ & $26.4^{*}(18)$ & N/A (22) & 7.1 & Dyshormonogenesis; IUGR & $15.3(6)$ & \\
\hline 5 & 3.08 & 38 & $\mathrm{~N}$ & $14.3^{*}(15)$ & $52.45(24)$ & 6.6 & $\begin{array}{l}\text { Confirmed CH but cause unknown (no uptake on RIS but on L-T4 for }>4 \text { weeks } \\
\text { prior to imaging) }\end{array}$ & $13.7(6)$ & \\
\hline 6 & 3.52 & 40 & $\mathrm{~N}$ & $34.9 *(14)$ & $>100(16)$ & 6.0 & Dyshormonogenesis (confirmed TPO defect) & $10.16(5)$ & \\
\hline 7 & 1.66 & 28 & Y & $32.3(4)$ & $27.0(9)$ & 7.5 & $\begin{array}{l}\text { Respiratory distress syndrome with small IVH in perinatal period). Confirmed CH } \\
\text { (TSH } 15.9 \mathrm{mU} / \mathrm{L} \text { after }>1 \text { year on L-T4 therapy) }\end{array}$ & & \\
\hline \multicolumn{10}{|c|}{ Status uncertain } \\
\hline 8 & 3.5 & 39 & Y & $15.0+(25)$ & $11.2(29)$ & 6.6 & Interrupted aortic arch and Di George (died aged 3 months) & $10(6)$ & $20(16)$ \\
\hline 9 & 1.04 & 29 & Y & $21.0 *(15)$ & $41.8(17)$ & 7.2 & Down syndrome with AVSD and chronic lung disease (died aged 6 months) & $7.4(6)$ & 75 (23) NB after vTFTs \\
\hline 10 & 1.49 & 31 & N & $21.0^{*}(10)$ & $150(15)$ & $<5.0$ & PDA (resolved). No imaging performed. Still on L-T4 & $5.77(5)$ & $\begin{array}{l}48.4(17) \text { NB after } \\
\text { vTFTs }\end{array}$ \\
\hline \multicolumn{10}{|c|}{ Transient TSH elevation } \\
\hline 11 & 3.83 & 40 & $\mathrm{~N}$ & $27.0 *(27)$ & N/A (36) & 9.7 & No imaging; treatment never started & $16(4)$ & \\
\hline 12 & 2.9 & 37 & Y & $15.0 *(18)$ & $110(24)$ & 4.8 & ECMO for Group B Streptococcus sepsis & $14(14)$ & \\
\hline 13 & 3.65 & 37 & N & $33.0^{*}(18)$ & $75.0(22)$ & 9.8 & PAX8 mutation and thyrotropin receptor polymorphism & $9(6)$ & \\
\hline 14 & 3.01 & 37 & Y & $9.8(10)$ & $73.5(17)$ & 5.1 & Renal and lung dysplasia, imperforate anus & & $\begin{array}{l}182.03 \text { (39) NB after } \\
\text { vTFTs }\end{array}$ \\
\hline 15 & 1.01 & 27 & Y & $11.2+(28)$ & $17.9(36)$ & 9.4 & Preterm/VLBW & $\begin{array}{l}1.49 \text { (5) at } 28 \text { weeks } \\
\mathrm{GA}\end{array}$ & $11.8(25)$ \\
\hline
\end{tabular}

*Repeat sample.tSecond repeat sample.

AVSD, atrioventricular septal defect; BW, birthweight; $\mathrm{CH}$, congenital hypothyroidism; cTSH, capillary thyroid-stimulating hormone; ECMO, extra-corporeal membrane oxygenation; $\mathrm{fT} 4$, free thyroxine; GA, gestational age; IUGR, intrauterine growth

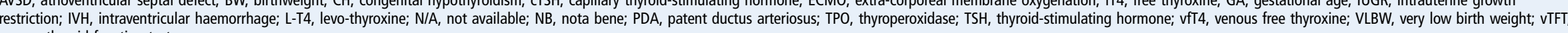
venous thyroid function test. 
detecting venous fT $4<10 \mathrm{pmol} / \mathrm{L}$ with a capillary TSH cut-off of $>40 \mathrm{mU} / \mathrm{L}$ (area under the ROC curve 0.83494).

\section{Venous fT4 levels according to capillary TSH cut-off in infants screened between 2002 and 2013 using the AutoDELFIA method}

Figure 3 shows a box and whisker plot of fT4 values grouped according to capillary TSH ranges. Median venous fT4 was $15 \mathrm{pmol} / \mathrm{L}$ for capillary TSH values of between 0 and $20 \mathrm{mU} / \mathrm{L}$ $(\mathrm{n}=53)$. Median $\mathrm{fT} 4$ was also $15 \mathrm{pmol} / \mathrm{L}$ for capillary TSH values of $20-40 \mathrm{mU} / \mathrm{L}(\mathrm{n}=48) ; 11$ for values of $40-60 \mathrm{mU} / \mathrm{L}$ $(\mathrm{n}=28) ; 11$ for values of $60-80 \mathrm{mU} / \mathrm{L}(\mathrm{n}=19)$ and $5 \mathrm{pmol} / \mathrm{L}$ when capillary TSH was $>80 \mathrm{mU} / \mathrm{L}(\mathrm{n}=138)$.

\section{ANALYSIS OF PATIENTS SCREENED BETWEEN 2002 AND 2013 WITH VENOUS FT4 <10 PMOL/L IN WHOM CAPILLARY TSH WAS $\leq 40 \mathrm{MU} / \mathrm{L}$}

Of the 154 patients with frankly subnormal fT 4 of $<10 \mathrm{pmol} / \mathrm{L}$, $15(9.7 \%)$ had capillary TSH values at the time of referral of $<40 \mathrm{mU} / \mathrm{L}$ and their details are given in table 2 . All but three had been referred after a repeat capillary TSH had been requested, and two infants (patients 8 and 15) were referred after the second repeat. Seven infants were found to have true hypothyroidism, five had transient TSH elevation and status was uncertain in three patients, of whom two died. Although venous TSH was higher than capillary TSH (consistent with assay differences and also with a rise having occurred between capillary and venous sampling), the degree of elevation was modest in relation to the venous $\mathrm{fT} 4$ being $<10 \mathrm{pmol} / \mathrm{L}$. Thus, venous TSH was $<30 \mathrm{mU} / \mathrm{L}$ in four patients (patients $1,7,8,15$ ) and only $30-60 \mathrm{mU} / \mathrm{L}$ in a further four patients (patients $2,3,5,9$ ). Moreover, fT4 was severely reduced at $<5 \mathrm{pmol} / \mathrm{L}$ in three of the patients (patients 1, 10,12).

\section{DISCUSSION}

This study shows that even when capillary TSH is only just above the Scottish threshold for referral ( $\geq 8 \mathrm{mU} / \mathrm{L})$, there is a risk that venous thyroid hormones will be low. This was the case in 15 infants who were found to have frankly low venous fT4 $(<10 \mathrm{pmol} / \mathrm{L})$ on initial venous sampling despite only mild capillary TSH elevation, ranging between 9.5 and $34.9 \mathrm{mU} / \mathrm{L}$. Thus, two infants with subnormal fT4 (patients 1 and 14 in table 2) had capillary TSH values of $<10 \mathrm{mU} / \mathrm{L}$, while three (patients 8,12 and 15) had values between 10 and $20 \mathrm{mU} / \mathrm{L}$ and two (patients 9 and 10) had values between 20 and $25 \mathrm{mU} / \mathrm{L}$. These findings are in keeping with work from Italy showing that capillary TSH cut-offs of 10 and $12 \mathrm{mU} / \mathrm{L}$ were superior to $20 \mathrm{mU} / \mathrm{L}$ in detecting thyroid dysgenesis. ${ }^{12}$ It follows that infants referred with capillary TSH elevation values just above the national or regional screening threshold should be investigated promptly, since true congenital hypothyroidism may be discovered in this situation.

In the present study, data from 1979 to 2002 (before the current assay came into use) show that while a threshold of $>40 \mathrm{mU} / \mathrm{L}$ for capillary TSH was sensitive in predicting a low fT4, specificity was much lower. By contrast, data from 2002 to 2013 using the AutoDELFIA assay give information of superior predictive value, demonstrating that just over $90 \%$ of infants who are found to have venous fT $4<10 \mathrm{pmol} / \mathrm{L}$ will have capillary TSH values of $\geq 40 \mathrm{mU} / \mathrm{L}$.

The infants with modest capillary TSH elevation (values ranging between 8 and $40 \mathrm{mU} / \mathrm{L}$ ) tended to be those requiring repeat sampling rather than direct referral. Thus, over half of the infants referred with capillary TSH values of $\leq 40 \mathrm{mU} / \mathrm{L}$ had been referred after a second (or in four cases a third) capillary test.
Analysis of the current study suggests that if capillary TSH is $>40 \mathrm{mU} / \mathrm{L}$, it is advisable to institute $\mathrm{L}-\mathrm{T} 4$ treatment without delay unless venous TFTs are available on the same day, since the specificity of $66 \%$ for predicting a venous fT4 of $10 \mathrm{pmol} / \mathrm{L}$ means that only $34 \%$ of such infants will have fT4 values of $\geq 10 \mathrm{pmol} / \mathrm{L}$. By contrast, if capillary TSH is $\leq 40 \mathrm{mU} / \mathrm{L}$ and the results of venous TFTs are not going to be available on the same day, there is a case for deferring L-T4 treatment. This should only be considered in situations when the infant is clinically euthyroid and when venous blood results will be available within a few days. The interval between the capillary TSH test leading to referral (whether initial, first or second repeat) should also be taken into consideration.

An alternative approach is to 'play safe' and to always institute L-T4 treatment in any infant with initial capillary TSH $\geq 25 \mathrm{mU} / \mathrm{L}$ or repeat capillary $\mathrm{TSH} \geq 8 \mathrm{mU} / \mathrm{L}$ in whom the venous blood results are not immediately available. However, this strategy deprives the clinician of being able to observe the venous TSH and fT4 trends when the latter are within the reference range, may adversely affect uptake on radioisotope scanning due to TSH suppression $^{13}$ and may commit the infant and family to 2 or 3 years of potentially unnecessary treatment, followed by the need for re-evaluation.?

We conclude that in situations where it is not feasible to obtain the results of venous blood tests on the same day, those infants with capillary TSH values of $\leq 40 \mathrm{mU} / \mathrm{L}$ who appear clinically well with no symptoms or signs of hypothyroidism (eg, jaundice, poor feeding, cold extremities) and in whom blood results will be available shortly do not necessarily require immediate treatment. However, immediate treatment is advised when the infant is symptomatic irrespective of the capillary TSH level.

Contributors Data for this paper were provided by SS and JJ, collated and analysed by TP and the paper was written by MDCD with the help of MGS, TP, JJ and SS.

\section{Competing interests None declared.}

Provenance and peer review Not commissioned; externally peer reviewed.

Open Access This is an Open Access article distributed in accordance with the Creative Commons Attribution Non Commercial (CC BY-NC 4.0) license, which permits others to distribute, remix, adapt, build upon this work non-commercially, and license their derivative works on different terms, provided the original work is properly cited and the use is non-commercial. See: http://creativecommons.org/ licenses/by-nc/4.0/

\section{REFERENCES}

1 Deladoey J, Ruel J, Giguère $Y$, et al. Is the incidence of congenital hypothyroidism really increasing? A 20-year retrospective population-based study in Quebec. J Clin Endocrinol Metab 2011;96:2422-9.

2 Grosse SD, Van Vliet G. Prevention of intellectual disability through screening for congenital hypothyroidism: how much and at what level? Arch Dis Child 2011;96:374-9.

3 Ray M, Muir T, Kennedy R, et al. An audit of congenital hypothyroidism in Scotland 1979-1993. Arch Dis Child 1997;76:411-15.

4 Rovet JF. Children with congenital hypothyroidism and their siblings: do they really differ? Pediatrics 2005;115:e52-7.

5 Oerbeck B, Sundet K, Kate BF, et al. Congenital hypothyroidism: no adverse effects of high dose thyroxine treatment on adult memory, attention, and behaviour. Arch Dis Child 2005;90:132-7.

6 Léger J, Ecosse E, Roussey M, et al., French Congenital Hypothyroidism Study Group. Subtle health impairment and socioeducational attainment in young adult patients with congenital hypothyroidism diagnosed by neonatal screening: a longitudinal population-based cohort study. J Clin Endocrinol Metab 2011;96:1771-82.

7 Léger J, Olivieri A, Donaldson M, et al., ESPE-PES-SLEP- JSPE-APEG-ISPAE, and the Congenital Hypothyroidism Consensus Conference Group. European Society for Paediatric Endocrinology consensus guidelines on screening, diagnosis and 
management of congenital hypothyroidism. J Clin Endocrinol Metab 2014;81:80-103.

8 Mutlu M, Karaguzel G, Alıyazicioğlu Y, et al. Reference intervals for thyrotropin and thyroid hormones and ultrasonographic thyroid volume during the neonatal period. J Matern Fetal Neonatal Med 2012;25:120-4.

9 Jones JH, Mackenzie J, Croft GA, et al. Improvement in screening performance and diagnosis of congenital hypothyroidism in Scotland 1979-2003. Arch Dis Child 2006:91:680-5.

10 Perry RJ, Maroo S, Maclellan AC, et al. Combined ultrasound and isotope scanning is more informative in the diagnosis of congenital hypothyroidism than single scanning. Arch Dis Child 2006;91:972-6.
11 Jones JH, Gellén B, Paterson WF, et al. Effect of high versus low initial doses of L-thyroxine for congenital hypothyroidism on thyroid function and somatic growth. Arch Dis Child 2008;93:940-4.

12 Corbetta C, Weber G, Cortinovis F, et al. A 7-year experience with low blood TSH cutoff levels for neonatal screening reveals an unsuspected frequency of congenital hypothyroidism (CH). Clin Endocrinol (Oxf) 2009;71:739-45.

13 Lucas-Herald A, Jones J, Attaie M, et al. Diagnostic and predictive value of ultrasound and isotope thyroid scanning, alone and in combination, in infants referred with thyroid-stimulating hormone elevation on newborn screening. J Pediatr 2014;164:846-54. 